\title{
AFORÇA DE TRABALHO EM ENFERMAGEM E SUA INSERÇÃO NO SISTEMA DE ALOJAMENTO CONJUNTO ${ }^{1}$
}

\author{
NURSING WORKFORCEAND ITS INSERTION IN THE ROOMING-IN \\ SYSTEM \\ LAFUERZA DE TRABAJO EN ENFERMERIA Y SU INSERCIÓN EN EL \\ SISTEMADEALOJAMIENTO CONJUNTO
}

Marisa Monticelli ${ }^{2}$

\begin{abstract}
RESUMO: Trata-se de uma reflexão teórica que aponta as características da força de trabalho em enfermagem em unidades de alojamento conjunto. Circunscreve-se, tendo como fio condutor, a importância que estes trabalhadores têm no cuidado às familias de recém-nascidos em instituiçőes hospitalares. O referencial adotado para a construção argumentativa do texto está centrado em estudos e autores que vislumbram o processo de trabalho em saúde e em enfermagem, bem como na compreensão da enfermagem como prática social e histórica. A reflexão é construida, inicialmente, buscando algumas considerações sobre a organização e a divisão do trabalho em saúde e em enfermagem. Também elabora-se observações pontuais sobre a origem formal e legal dos trabalhadores de enfermagem brasileiros para, finalmente, construir alguns subsidios que caracterizem a força de trabalho em enfermagem e, especificamente, no processo de trabalho desenvolvido por agentes de enfermagem de diferentes niveis, nos sistemas de alojamento conjunto das instituições-maternidades. Conclui-se que o trabalho desenvolvido nestas unidades exige que os profissionais de enfermagem tenham qualificação para assistir o recém-nascido, a puérpera e a familia, além de possuirem dominio teórico/técnico para lidarem com instrumentos (meios) que não são usuais, em sua maioria, nos serviços de saúde.
\end{abstract}

PALAVRAS-CHAVE: força de trabalho, processo de trabalho, alojamento conjunto

\section{INTRODUÇÃo}

Força de trabalho é um termo clássico, consagrado pela economia política e que vem sendo utilizado, através dos tempos, em diversos campos cientificos. Seu uso vincula-se, principalmente, à descrição e análise da natureza do processo de trabalho, ligando o trabalhador ao processo de produção, influenciando e sendo influenciado por este processo.

Marx (1975, p. 187) entendia a força de trabalho como "o conjunto das faculdades físicas e mentais, existentes no corpo e na personalidade viva de um ser humano, as quais ele põe em ação toda vez que produz valores-de-uso de qualquer espécie".

No que diz respeito à força de trabalho em saúde, Nogueira (1987) o assume como se referindo ao conjunto de pessoas vinculadas direta ou indiretamente à prestação de serviços de saúde e sujeitas a uma relação de compra e venda dessa mercadoria especial constituída pela capacidade de trabalho de cada um. Assim, a qualificação profissional é um importante atributo da força de trabalho, mas não o único fator que contribui para a visão analítica mais geral que se

\footnotetext{
'Estudo realizado no contexto da disciplina "Processo de Trabalho em Saúde e Enfermagem", do Curso de Doutorado em Enfermagem da Universidade Federal de Santa Catarina (UFSC).

${ }^{2}$ Enfermeira. Professora Adjunto do Departamento de Enfermagem da UFSC. Doutoranda em Enfermagem.
} 
proponha fazer. É necessária uma perspectiva histórica, que traduza o devir da força de trabalho, quando se quer refletir sobre a inserção destes trabalhadores nos dias atuais.

Para falar da força de trabalho em enfermagem, há que se constituir um percurso amplo, de processo e não de produto, em que os viéses particulares possam ser redesenhados num cenário de enfoque diacrônico. Para isto, pretendo revisitar um pouco as finalidades do trabalho em saúde e enfermagem, a divisão do trabalho e o processo de institucionalização da enfermagem brasileira, para depois refletir sobre a força de trabalho dos elementos da enfermagem em unidades de Alojamento Conjunto. Este texto se circunscreve tendo como objetivo a reflexão sobre a importância que estes trabalhadores têm no cuidado às família de recém-nascidos em instituiçōes hospitalares.

\section{O TRABALHO EM SAÚDE E EM ENFERMAGEM: ALGUMAS CONSIDERAÇÖES SOBRE SUA ORGANIZAÇÃO E DIVISĀO}

A compreensão da enfermagem como trabalho ou como prática social e histórica toma seus contornos ao articular-se com as demais práticas da sociedade. Portanto, desenvolve-se no calor das forças produtivas e das relações de produção em um dado momento histórico. $A$ enfermagem constrói os seus conhecimentos e desenvolve seus manejos e práticas com a finalidade de (pelo menos em tese - pois este é um indicativo ainda não inteiramente consensual) transformar o processo saúde-doença, a fim de contribuir para a saúde dos indivíduos e das coletividades, por meio do seu processo de trabalho. É uma atividade realizada predominantemente por mulheres que precisam da profissão para reproduzirem a sua própria existência. A enfermagem lida, em todas as áreas de atuação, com as necessidades ou carecimentos humanos que, por sua vez, não são sempre naturais, mas produzidos nas relações culturais e sociais. Os elementos profissionais da enfermagem e os individuos ou comunidades, com suas carências atuais e potenciais, relacionam-se também com outros seres humanos, através de seus produtos, na divisão do trabalho (Almeida e Rocha, 1997, Fonseca, 1995).

O trabalho de enfermagem é considerado como parte do trabalho em saúde e, como diz Mendes Gonçalves (apud Kantorski, 1997), não pode ser tomado como mercadoria imediata, pois não produz bens materiais imediatos que servem como meio de produção de mais-valia $\mathrm{e}$ acumulação de capital. Para Pires (1998, p. 160), o trabalho em saúde é parte do setor de serviços. "É um trabalho da esfera da produção não-material, que se completa no ato de sua realização. Não tem como resultado um produto material independente do processo de produção e comercializável no mercado. O produto é indissociável do processo que o produz, é a própria realização da atividade".

O setor saúde, apesar de não gerar mercadoria concreta, objetiva, palpável, encontra-se intrinsecamente sustentado pela racionalidade e pela produtividade do modelo capitalista. Estes principios confundem-se com o próprio modo de atuar em saúde, onde o parcelamento e a subdivisão de tarefas denuncia a divisão pormenorizada do trabalho.

A divisăo do trabalho deu-se de formas diferentes, de acordo com os diversos modos de produção em cada momento histórico. A separação entre concepção do trabalho e execução do mesmo não é especifica do modo de produção capitalista, mas é no seu seio que a divisão do trabalho toma-se pormenorizada. O produto, ao ser feito, toma-se fugidio: passa por numerosos procedimentos, desempenhados por uma diversidade de trabalhadores, os quais, muitas vezes, não têm possibilidades de controlar nem o processo de trabalho e nem o produto resultante.

$\mathrm{Na}$ saúde, a divisão do trabalho quase que se confunde com o processo de institucionalização. São vários os estudiosos brasileiros que têm contribuido para a construção do conhecimento nesta área. Estes estudos revelam que, antes do aparecimento do espaço institucional (o hospital, por excelência), os exercentes do trabalho em saúde desenvolviam as suas ações quase que de forma interdependente, como resultado da divisão social do trabalho. 
Pode-se entender que quase não havia o estabelecimento compulsivo de um trabalho parcelar. Porém, com a evolução das instituições hospitalares, o médico toma para si a gerência do ato assistencial em saúde, delegando funções aos outros trabalhadores de saúde.

Ao ser eleito como o espaço terapêutico de excelência para a relação médico-paciente (posição higienista), o hospital foi organizado de modo que os "outros" trabalhadores e serviços pudessem dar conta do trabalho médico. Surge assim a primeira extensão do médico em um trabalho coletivo (Mendes Gonçalves, citado por Almeida e Rocha, 1997). Deste modo, o trabalhador médico passou a ser um "trabalhador cooperativo".

No Brasil, a enfermagem organiza-se como profissão também sob o modo capitalista de produção, integrando o trabalho coletivo. No processo de institucionalização do trabalho em saúde coube a ela as funções mais "manuais" que diziam respeito a assistência aos pacientes internados. Enquanto à enfermeira coube o controle do processo de trabalho, os instrumentos, os saberes e as técnicas de administração, aos outros elementos da equipe de enfermagem coube a realização do cuidado propriamente dito.

Enquanto trabalho coletivo, o trabalho da enfermagem ocorre por distribuição de partes dele entre os seus diversos agentes. Neste processo, as operações são hierarquizadas por complexidade de concepção e execução. Sem dúvida, isto exige habilidades diferentes dos diferentes elementos do trabalho coletivo para a manipulação dos instrumentos de trabalho. No entanto, como se poderia pensar, este fato não revela uma simples divisão de tarefas para facilitar o trabalho. Segundo Rosa et al. (1989, p. 102), "sendo todo o trabalho, intelectual ou manual, simples ou complexo, correspondente à historicidade do desenvolvimento da sociedade como um todo, o acesso dos ajustes aos seus conteúdos técnico-científicos tem ocorrido numa escala hierarquizada".

\section{ORIGEM FORMAL E LEGAL DOS TRABALHADORES DE ENFERMAGEM BRASILEIROS: OBSERVAÇÕES PONTUAIS}

As origens da enfermagem moderna, que emergem a partir de Florence Nightingale, mostram que a enfermagem nasceu dividida em dois estratos sociais distintos, coerente com o modelo capitalista. Às ladies cabia o pensar, concretizado nos postos de comando a às nurses o fazer sob a direção das primeiras. De acordo com Rezende (1986), o trabalho manual, considerado "inferior" podia ser executado por individuos socialmente inferiores, excluídos do pensar, e o trabalho intelectual, considerado "superior", requeria individuos advindos de camadas superiores da sociedade. Assim, a divisão social, conforme revela a história, precedeu a divisão técnica do trabalho coletivo em enfermagem.

No Brasil, antes do processo de institucionalização, "os precursores da enfermagem profissional eram religiosos que prestavam cuidados nas instituições religiosas, as parteiras e as voluntárias leigas" (Pires, 1998, p.92). É somente no final do século XVII que os registros históricos focalizam o nome da voluntária Francisca Sande, como uma pessoa reconhecida socialmente por exercer atividades de enfermagem. A organização da enfermagem profissional brasileira, enquanto um processo de instrução formal somente aparece de modo ainda incipiente, no século XIX.

Em 1890 surge a Escola Alfredo Pinto, a primeira com o propósito de formar enfermeiros e enfermeiras, mas ainda assim, organizada e controlada por médicos. Estes, já reconhecidos como integrantes de uma profissão institucionalizada no campo da saúde. Mas a enfermagem só passaria a ter uma formação profissional independente, no Brasil, com a criação da Escola Ana Neri, no Rio de Janeiro, no ano de 1923. "O modelo de formação segue os princípios nightingaleanos e, logo, os enfermeiros formados passam a formar pessoal auxiliar para o exercício das tarefas delegadas de cunho predominantemente manual" (Pires, 1998, p. 93). Também é somente nesta década que as parteiras (agora não mais independentes, mas treinadas 
pelos médicos e a eles subordinados) passam a integrar o trabalho profissional de enfermagem. Logo após a diplomação das primeiras turmas da escola Ana Neri, as enfermeiras egressas foram absorvidas por Departamentos Estatais e também atuaram em vários Estados, na formação de enfermeiros e auxiliares de enfermagem. Estes últimos, formados para exercer cuidados e tarefas manuais delegadas pelas enfermeiras em instituições hospitalares. Inicia-se aí o controle formal do trabalho auxiliar, pelas enfermeiras, atendendo às necessidades dos donos dos hospitais em gastar menos com a remuneração do trabalho.

Somente em 1936, com a criação do primeiro curso de formação de auxiliares, agregado à Escola Carlos Chagas, em Belo Horizonte, é que ficou instituída a existência de cursos de formação de auxiliares de enfermagem em caráter permanente. Mas é a Lei $n^{\circ} 775$ de 1949 que institucionaliza, em definitivo, os critérios e o tempo de formação dos auxiliares de enfermagem (Pires, 1989).

$\mathrm{Na}$ década de 50 , com o fortalecimento da política previdenciária brasileira, e sendo insuficiente o número de trabalhadores de enfermagem, os enfermeiros passaram a ser absorvidos no mercado para exercerem funções de administradores e supervisores da equipe de enfermagem. Este contexto foi vital para a expansão da enfermagem hospitalar, atendendo assim à necessidade da tecnologia institucional e da economia previdenciária (Medeiros, 1997).

A crescente necessidade de mão-de-obra qualificada nas instituições hospitalares fez com que se elevasse cada vez mais a força de trabalho em enfermagem, principalmente auxiliares e atendentes de enfermagem que se encarregavam e ainda hoje encarregam-se da maior parte dos serviços hospitalares, subordinando-se aos médicos, aos enfermeiros e às regras institucionais que a todos regulam.

Com a Lei 2.604/55, que regulava até 1986 o exercício da enfermagem profissional, oficializa-se a divisão do trabalho na enfermagem em categorias: enfermeiros, auxiliares de enfermagem, parteiras e práticos de enfermagem, dentre eles o atendente de enfermagem.

A discussão sobre o técnico de enfermagem surgiu apenas no início da década de 50 e assim mesmo com grandes discussões e conflitos no interior da Associação Brasileira de Enfermagem - , quando houve a proposição do ensino em três niveis, conforme proposta governamental, tendo em vista a articulação de cursos que a Lei de Diretrizes e Bases da Educação Nacional (LDB) de então permitia, com o objetivo que os integrantes da equipe de enfermagem tivessem a possibilidade de progredir processualmente um nivel após o outro. Mas foi somente com a promulgação da LDB $n^{\circ} 4024$ de 1961 que a formação do técnico de enfermagem pode se efetivar, cujos cursos foram iniciados em 1966 pelas Escolas de Enfermagem Ana Neri e Luiza de Marilac (Torrez, 1996).

Mas são os atendentes de enfermagem um capítulo à parte na organização e desenvolvimento da enfermagem brasileira. Ainda hoje, continuam sendo a mão-de-obra mais utilizada nos hospitais, apesar da nova legislação (Lei do Exercício Profissional, $n^{\circ} 7.498 / 86$ ) que estabeleceu o prazo para que só exercessem a enfermagem: enfermeiros, técnicos e auxiliares de enfermagem. O que se observa, corriqueiramente, é que muitas instituições deixaram de contratá-los como "atendentes de enfermagem", substituindo a contratação do mesmo trabalhador, para desempenho das mesmas ações, com outros nomes, a fim de manter atualizado e de modo legal, o número de pessoal qualificado em seus quadros (Pires, 1998).

Este trabalhador, apesar de existir desde que se institucionaliza a enfermagem, atua sem ter uma qualificação formal para o seu exercício, tendo sido, historicamente, treinado em serviço para a realização de determinadas funções. Sua inserção é um assunto pertinente à história da prática profissional, ligada às condições sócio-políticas e econômicas. Estas condições favoreceram o crescimento da categoria de atendentes de enfermagem que têm contribuído para a profissão. Contudo, ao mesmo tempo, tem trazido dificuldades por não terem formação profissional adequada e realizarem atividades junto aos clientes, embora não tenham nenhum respaldo formal para serem considerados profissionais de enfermagem (Bezerra et al. 1998). 
Bezerra et al (1998) chamam a atenção para o fato de que o parágrafo único da Lei ${ }^{\circ}$ 7.498 , que limitava a presença de pessoal sem formação específica nas instituições, foi modificado através da Lei 8.967/94, assegurando aos atendentes admitidos até a vigência desta última lei, o exercício das atividades elementares de enfermagem, devendo continuar a ser orientados e supervisionados por enfermeiros. Esta questão certamente continua comprometendo a qualidade dos serviços prestados à população, ao mesmo tempo que continua colaborando para a opressão e alienação destes exercentes da enfermagem, enquanto força de trabalho.

\section{SUBSÍDIOS GERAIS PARA CARACTERIZAR A FORÇA DE TRABALHO EM ENFERMAGEM}

De modo geral, a força de trabalho em enfermagem no Brasil é representada pelo enfermeiro, pelo técnico de enfermagem, pelo auxiliar de enfermagem e pelo atendente de enfermagem. Este último, conforme foi observado anteriormente, também tem sido empregado nas instituições de saúde com a denominação de auxiliar de serviços gerais, agente de atividades de saúde, agente operacional, dentre outras denominações.

A profissão de enfermagem, embora possua o seu exercício regulamentado, com as diversas e diferentes atribuições previstas na legislação pertinente - que, inclusive, confirma a divisão interna da categoria - ainda não avançou de modo consensual na direção de imprimir uma finalidade inequivoca ao seu trabalho; nem mesmo tem claro qual seu objeto de trabalho e, em conseqüência, quais são as relações entre este objeto e os trabalhadores da enfermagem.

Se entendermos que as finalidades de qualquer trabalho, em qualquer profissão, influenciam, ou melhor, determinam a força de trabalho que precisa ser empregada para perseguilas, então fica claro que a enfermagem ainda anda às voltas quanto à apreensão do seu objeto e também sobre qual a melhor forma de desenvolver o trabalho de cada um dos elementos que compõe esta força de trabalho. Esta situação é mais contundente quando se trata de auxiliares de enfermagem, considerados profissionais de nivel médio, bem como os atendentes de enfermagem, a grande maioria de exercentes não qualificados.

Nogueira (1987) reflete que a terceirização da economia brasileira tem a particularidade de se dar às expensas de um amplo contingente de pessoal pouco qualificado e de pouca escolaridade, fenômeno que atua em detrimento da qualidade dos serviços prestados à população. Segundo este autor, a presença majoritária destes elementos tem as mesmas causas sociais que provocam, por exemplo, a incorporação maciça de professores de escassa qualificação em todos os recantos do pais, em ambos os casos, força de trabalho essencialmente assalariada e feminina. Além disso, têm uma natureza subordinada e desvalorizada de sua prática e possuem deficientes condições de trabalho.

Dados atuais sobre a força de trabalho em enfermagem, praticamente são inexistentes. Segundo a pesquisa nacional feita pela Associação Brasileira de Enfermagem e pelo Conselho Federal de Enfermagem em 1983, a composição da força de trabalho era de: $8,5 \%$ de enfermeiros; $6,6 \%$ de técnicos; $21,1 \%$ de auxiliares e de $63,8 \%$ de atendentes de enfermagem (Médici; Paim, 1987), representando $65 \%$ dos trabalhadores do setor saúde. No entanto, a força de trabalho cadastrada no Conselho Federal de Enfermagem nos mostra que no ano de 1998 a composição encontrava-se assim: $12,65 \%$ de enfermeiros; $11,63 \%$ de técnicos; $52,63 \%$ de auxiliares e $23,06 \%$ de atendentes e no ano de 1999 havia registros de $15,25 \%$ de enfermeiros; $15,00 \%$ de técnicos; $67,25 \%$ de auxiliares e apenas $2,48 \%$ de atendentes (Vale et al., 1999). Há que se considerar que estes percentuais não refletem completamente a complexidade da força de enfermagem no país, uma vez que os programas do Ministério da Saúde atuais abriram um espaço para a absorção de trabalhadores sem qualificação específica, "cujo número exato é desconhecido e crescente e, embora não estejam incluídos na enfermagem, é nele que eles vêm encontrando abrigo, treinamento e supervisão" (Vale et al., 1999, p.11).

Estudos sobre os recursos humanos em saúde no Mercosul, mostram que a enfermagem, 
em todos os paises integrantes, continua a ser uma profissão essencialmente feminina (entre $83 \%$ de mulheres na Argentina e quase $95 \%$ no Brasil) que, como a maioria das categorias profissionais, tende a concentrar-se nas grandes cidades. Ainda segundo dados destes estudos, observa-se que continua sendo uma prática exclusivamente dependente e assalariada que, atualmente, tem níveis de multiemprego e subemprego variáveis porém significativos e com difíceis condições de trabalho nos quatro paises (Campos; Brito; Rigoli, 1995).

Para Almeida e Rocha (1989), a questão da utilização de força de trabalho de enfermagem, principalmente de pessoal elementar, é uma grande preocupação. Ao mesmo tempo em que o seu trabalho é necessário (pois a divisão do trabalho de enfermagem tem-se mostrado, no capitalismo, ascendente), o controle social destes trabalhadores tem aumentado. Acresce-se a isto o fato de que nas instituições hospitalares o pessoal de enfermagem é, numericamente, o pessoal mais representativo.

Uma das caracteristicas mais gritantes na força de trabalho em enfermagem é a feminização. Mesmo quando a participação feminina no mercado de trabalho brasileiro ainda era reduzida (antes da década de 70), a enfermagem já figurava entre aquelas profissões que tinham maior número de mulheres empregadas nas instituições de saúde.

A partir de 1970 aumentou o número de mulheres no mercado de trabalho, fato este atribuido ao papel que o emprego feminino passou a ter na composição do orçamento doméstico (uma vez que os trabalhadores em geral sofreram perda do poder aquisitivo, advinda da política de arrocho salarial) e também ao fato de que a mulher lutou para que houvesse mudança cultural e, paulatinamente, foi obtendo maior aceitação no mercado de trabalho. A partir deste período, Médici (1987) observa que houve uma tendência similar quanto aos profissionais de saúde com nível médio e elementar. O crescimento passou de $46 \%$ (em 1970), para $68 \%$ (em 1980 ), significando um incremento de $189 \%$. Mas aponta que esta tendência também esteve relacionada à estrutura salarial mais baixa do emprego feminino.

Esta proporção também pode ser encontrada em estudos isolados, como aquele conduzido por Marsiglia (1992), onde a autora, ao pesquisar os funcionários públicos de unidades de saúde na cidade de São Paulo, encontrou uma crescente feminização da força de trabalho, decorrida da desvalorização da atividade no setor saúde e a pouca ou nenhuma exigência de qualificação profissional.

A identificação da enfermagem como profissão exercida por mulheres vem, há muito tempo, sendo uma conseqüência da divisão do trabalho, e também um fator de desvalorização da categoria, principalmente por ser considerada submissa e de baixo custo. Além disto, a dupla jornada de trabalho a que a mulher trabalhadora é submetida, dificulta um maior engajamento com as lutas da categoria (Capella; Gelbecke, 1988).

As origens da discriminação da mulher quase que se perdem na história da humanidade, adquirindo nuanças mais ou menos intensas de acordo com a época e o modo de produção vigente. Também tem origens históricas (e portanto origens construídas - não "naturais") a perspectiva de que é o homem que tem papel preponderante e hegemônico no campo da produção econômica.

O processo de profissionalização da enfermagem, como se viu anteriormente, abarcou em seu interior categorias diferenciadas com vinculações de classes distintas e, historicamente, definindo-se como profissão feminina, tem ocupado um status subordinado ao da categoria médica, definida ainda hoje, na sociedade ocidental, como profissão masculina (Silva, 1989). "A dominação médico-enfermagem não é só o resultado da dominação homem-mulher, mas a historicidade do papel de exclusão feminina certamente contribuiu na reprodução das relações de poder de dominação-submissão até hoje presentes no setor saúde" (Pires, 1989, p.58).

Ainda uma outra faceta relativa às relações de gênero na enfermagem se mostra, quando se analisa a perspectiva das categorias classe social e gênero. Esta relação revela uma diferenciação por mulheres e homens de diferentes classes sociais. Fonseca (1995), por exemplo, 
ao pesquisar os ingressantes de um curso de graduação em enfermagem observou que enquanto a maioria das mulheres pertence à burguesia ou suas frações, a maioria dos homens pertence ao proletariado, o que sugere que a valorização social do trabalho de enfermagem seja diferenciada também por diferentes classes sociais, em relação ao sexo.Outra questão que permeia o trabalho da enfermagem e que influencia na caracterização de sua força de trabalho é o seu assalariamento, cuja tendência mostra-se cada vez mais crescente. Este aspecto também se relaciona à parcela de exercentes femininos no contexto do mercado de trabalho. Além do fato de que os profissionais enfermeiros percebem um salário bem mais inferior do que a grande maioria de outros profissionais de mesmos niveis de escolaridade (médicos e odontólogos), a situação mais grave é justamente aquela dos profissionais de nivel médio e dos atendentes de enfermagem.

Em 1980, a maioria dos trabalhadores de saúde menos qualificados possuiam salários baixos, em ambos os sexos. Porém, a percentagem de mulheres com salário inferior era maior do que a dos homens (Machado, 1987).

No Brasil, a esmagadora maioria dos trabalhadores de enfermagem são assalariados, vendem sua força de trabalho ao empresário hospitalar ou ao Estado. O enfermeiro, apesar de assalariado e não participar dos lucros da empresa, tem a posição de gerente da assistência de enfermagem e, até certo ponto, da organização institucional (Almeida e Rocha, 1986).

Não bastasse as dificuldade salariais e a ainda freqüente desvalorização social destes trabalhadores, os postos de trabalho assegurados para o desempenho de suas atividades têm sido, como já se disse, as instituiçōes públicas e privadas de saúde, com grande concentração nos hospitais brasileiros.

A jornada de trabalho nestes locais, não é especial e nem fixada em lei, mas é uma importante questão, pois os horários são bastante atipicos. O trabalho noturno, o trabalho alternado e os regimes de plantões, assim como as jornadas que iniciam muito cedo ou finalizam muito tarde, interferindo no sono e dificultando a conciliação entre vida familiar e social são especificidades do trabalho na enfermagem que precisam ser consideradas (Lopes, 1992).

Mas são as funçōes desempenhadas pelos diferentes elementos que merecem atenção especial. Na maioria das vezes desenvolvem, como equipe, atividades parcelares e muitas vezes desarticuladas.

Os trabalhadores de enfermagem, conforme se observou, possuem diferenciados graus de formação e dividem o trabalho a ser realizado. Esta divisão garante ao enfermeiro o papel de detentor do saber e de controlador do processo de trabalho da enfermagem, cabendo aos demais elementos (técnico, auxiliar e atendente) o papel de executores de tarefas delegadas (Pires, 1998).

Esta divisão se encontra nas origens da enfermagem, continuando no decorrer do século XX, principalmente nos Estados Unidos e também no Brasil. No ensino e na prática da enfermagem era enfatizada a aprendizagem das técnicas voltadas primeiramente para o procedimento executado, viabilizando o controle social dos auxiliares, o que possibilitou uma prática de enfermagem denominada de "modalidade funcional", onde a racionalidade do trabalho consistia em distribuir as tarefas de acordo com sua complexidade e nivel de competência profissional (Almeida; Rocha, 1989).

Esta modalidade de assistência firmou-se, segundo Pires (1998) e Almeida e Rocha (1989), com os trabalhos de Taylor, que tratava da gerência cientifica, nos quais a liderança de enfermagem foi buscar subsídios para o trabalho nos hospitais. A dimensão prática das técnicas de enfermagem viabilizou-se em duas direções que são partes do mesmo processo de trabalho em enfermagem, ou seja, a direção e a execução, os aspectos administrativos e assistenciais do cuidado da enfermagem. Estes aspectos resultam na divisão pormenorizada do trabalho, onde as enfermeiras administram e planejam e os outros elementos da equipe executam (Almeida; Rocha, 1989). 
A Lei do Exercício Profissional atualmente vigente mantém a lógica da divisão pormenorizada do trabalho, explicitando as atividades que são privativas do enfermeiro e definindo as atividades dos demais elementos. Dentre as privativas do enfermeiro, reconhece a prestação de cuidados de enfermagem que são considerados tecnicamente mais complexos, fundamentados cientificamente e que exijam capacidade na tomada de decisões imediatas. A Lei também estabelece que cabe ao auxiliar as atividades de nivel médio, de natureza repetitiva e sob a supervisão do enfermeiro. Ao técnico cabe exercer atividades também de nivel médio, envolvendo orientação, acompanhamento e supervisão do trabalho de enfermagem em grau auxiliar. $\mathrm{O}$ atendente de enfermagem, logicamente, não tem mais suas funções previstas em lei, pelo próprio caminho proposto de profissionalizá-lo, embora continue a realizar atividades diretas e indiretas aos clientes hospitalizados.

As discussões e reflexões realizadas no seio da categoria mostram a enorme dificuldade em se definir o que seja ou não complexo no cuidado à clientela. Almeida e Rocha (1989), por exemplo, questionam: "Seriam as atividades de cuidado direto ao paciente as mais simples e as administrativas mais complexas?". Mas não é só a categoria que traz à tona esta preocupação. Nogueira (1987, p. 17) também coloca que é justamente aos atendentes e auxiliares que cabe uma quantidade expressiva de funçöes, "umas realmente simples, mas outras requerem perícia e certo senso crítico, mas para as quais eles não têm preparo adequado, seja no tocante aos aspectos de educação geral, seja no tocante à capacitação profissionalizante propriamente dita".

Pires (1998), em sua recente pesquisa realizada em dois grandes hospitais (um público e um privado) brasileiros, constatou que em unidades clínicas, a assistência de enfermagem ora é desenvolvida sob a modalidade funcional (divisão por tarefas) - a forma mais comum de desempenho na grande maioria dos hospitais brasileiros - , ora sob a modalidade integral (que rompe, ao menos parcialmente, com a divisão por tarefas). Segundo a autora, na modalidade de cuidados funcionais o trabalhador de enfermagem (técnico, auxiliar ou atendente) desenvolve um trabalho rotineiro, não tendo uma visão global do paciente, o que dificulta o entendimento de todo o processo de trabalho. Em algumas situaçōes, inclusive, prestam toda a assistência, independente do seu nivel de formação.

A autora também chama a atenção de que, apesar de alguns auxiliares e técnicos desenvolverem suas atividades em forma de rodizio, o cotidiano do trabalho se mostra alienante. "É a repetição de técnicas especificas e desintegradas. Quem executa o trabalho se exime do entendimento da totalidade e quem recebe a assistência tem dificuldade de saber a quem solicitar ajuda" (p. 190).

A modalidade de cuidados integrais, ainda segundo a autora, é mais freqüente em unidades de terapia intensiva, possibilitando uma visão mais global das necessidades do cliente, e o desenvolvimento de um trabalho mais criativo. No entanto, mesmo nesta modalidade assistencial, a lógica da separação entre o saber e o fazer permanece.

\section{ALOJAMENTO CONJUNTO: CONSIDERAÇÖES SOBRE A FORÇA DE TRABALHO EM ENFERMAGEM}

O alojamento conjunto, de modo genérico, é compreendido como um sistema hospitalar em que o recém-nascido sadio, logo após o nascimento, permanece ao lado da mãe, 24 horas por dia, num mesmo ambiente, até a alta hospitalar, estimulando-se a participação do pai e da familia. Este sistema dá-se sob a orientação e supervisão de uma equipe multiprofissional que inclui trabalhadores de enfermagem, médicos obstétras e neonatologistas, psicólogos, nutricionistas e assistentes sociais.

Sabe-se, porém, que a parturição, o partejamento e o cuidado com o recém-nascido tiveram por muito tempo a sua atenção desvinculada da prática médico-cirúrgica oficial. A prática 
histórica sempre foi permeada pelo trabalho essencialmente feminino. Os conhecimentos relativos ao parto e às atenções específicas ao binômio mulher-criança foram adquiridos através da tradição e da experiência empírica. O contexto social garantia a legitimação da prática da parteira que oferecia auxilio, conforto e proteção às parturientes em seus domicílios.

A entrada dos homens no cenário "de mulheres" não se deu, no entanto, sem conflitos. Kitzinger (1996) relata que os homens que começaram a fazer o trabalho das parteiras corriam sérios riscos. Na Inglaterra, os primeiros parteiros só foram reconhecidos no século XVII. Até esta época, um médico, a quem uma parteira solicitasse auxílio num parto difícil, "tinha de andar de gatas e de se esconder debaixo de um móvel" (p. 106); andavam às palpadelas debaixo da roupa de cama e durante o parto tinham que confiar inteiramente no sentido do tato.

No século XV, com o predomínio do mercantilismo, começaram a emergir algumas políticas que visavam a "melhoria das condições de vida da população". As práticas médicas, na Europa, passaram a ser regulamentadas pelo Estado e o trabalho das parteiras também passou por regulamentação e controle do Estado, emergindo conflitos entre parteiras e cirurgiões pela conquista da supremacia na área (Scochi et al., 1996).

Em decorrência da revolução científica ocorrida nos séculos XVI e XVII e no bojo do capitalismo emergente, o hospital foi se tornando o lugar privilegiado da atenção, da pesquisa, ensino e saber médico (Silva, 1989). As parteiras passam a ser institucionalizadas, assim como o próprio parto, e aquilo que era conhecimento adquirido na experiência e vivência empírica entre mulheres, passa a ser confiscado pelos médicos e seu trabalho amplamente subordinado a eles.

A medicina desenvolve-se nos séculos XVIII e XIX baseada na racionalidade científica moderna e vai se tornar instituição hegemônica de cuidado, inclusive ao parto e aos cuidados com o recém-nascido. A arte de partejar passou de ofício independente a atividade subordinada e controlada pala medicina (Pires, 1989).

A partir do século $X X$ as práticas do nascimento passam a predominar no espaço hospitalar e, nele, são ditados os rituais, as normas e as rotinas para tratamento e comportamento das mulheres e seus recém-nascidos fazendo, inclusive, com que a assistência a este último surgisse, na área da saúde, como um prolongamento da prática obstétrica (Scochi et al., 1996, Gomes, 1996).

Ao transferir o processo do nascimento, do seio da família, para o espaço hospitalar, não se deslocou apenas o locus do acontecimento, mas também e, indissociavelmente, passou-se a perceber o processo de nascer como dependente da tecnologia e do preparo formal de diversos especialistas e a conceber o processo de nascer como a expulsão ou a extração completa do corpo da mãe, de um "produto" da concepção (Monticelli, 1996). Assim, a idéia do nascimento como um processo universal e despersonalizado passou a ser dominante e ainda continua amplamente presente na atualidade.

A institucionalização do nascimento, durante muito tempo, separou mãe e filho. As puérperas eram isoladas em unidades obstétricas de puerpério, enquanto os recém-nascidos eram alojados em unidades de berçário. Esta prática, garantida pelo modelo hegemônico higienista, respondia à "necessidade científica" de evitar qualquer tipo de infecção, além de imprimir racionalidade ao trabalho, promovendo o controle dos corpos das mulheres e bebês, prevenindo-se riscos potenciais.

Embora esta prática ainda vigore em muitos hospitais brasileiros, tem havido uma tendência recente em "humanizar" as ações oriundas da atuação ao parto e ao nascimento, fazendo com que mães e filhos permaneçam juntos durante a internação. Esta filosofia humanizadora, no entanto, não é nova e nem mesmo os princípios norteadores e objetivos são uma "tendência".

Alojamento conjunto (Rooming-in) foi um termo usado pela primeira vez pelo americano Arnold Gessel, em 1943, para denominar a prática de acomodação da mãe e do filho em um 
mesmo ambiente, na instituição-maternidade. A partir dai outras experiências similares foram sendo colocadas em prática, principalmente com os resultados de estudos epidemiológicos e na área psicossomática, psicodinâmica e fisiologia aplicada ao comportamento, que constatavam os inconvenientes de caráter clínico-patológico causados pela concentração de recém-nascidos em berçários e os efeitos perversos da separação precoce mãe-filho (Kakehashi, 1996, Ungerer; Miranda, 1999, Scochi et al., 1996).

Mas não foram só os estudos cientificos, as instituições, os profissionais de saúde e as políticas governamentais que impulsionaram e incentivaram o desenvolvimento de alojamentos conjuntos. Um fator muito importante para a sua implementação deu-se a partir do próprio movimento social das mulheres e, particularmente, de um movimento iniciado nos Estados Unidos, em que as mulheres exigiram ficar junto com seus bebês "como uma forma de deplorar os custos psicológicos da segurança e conveniência médico-hospitalar, que insistiam em separar os recém-nascidos de suas mães por ocasião do parto" (Ungerer; Miranda, 1999, p. 7).

No Brasil, a prática de alojar conjuntamente puérperas e recém-nascidos não era freqüente até a década de 70 . Apenas as Santas Casas de Misericórdia acomodavam mulheres de baixa renda junto com seus filhos. Ungerer e Miranda (1999) referem que foi apenas em 1997 que o Ministério da Saúde recomendou que as crianças sem risco permanecessem ao lado de suas mães, e não mais em berçários.

Embora muitos Programas de Incentivo (principalmente ao aleitamento materno) tenham sido propostos por órgãos governamentais, neste interim, foi somente em 1993 que surgiu a portaria ministerial $n^{\circ} 1016$, de 26 de agosto, regulando as normas básicas para implantação do sistema de alojamento conjunto em todo o território nacional (Brasil, 1993). Esta portaria justifica a obrigatoriedade do sistema, considerando a necessidade de incentivar a lactação e o aleitamento matemo, favorecendo o relacionamento mãe/filho e o desenvolvimento de programas educacionais; a necessidade de diminuir o risco de infecção hospitalar, evitando as complicações maternas e do recém-nascido; o Estatuto da criança e do Adolescente que estabelece a obrigatoriedade do alojamento conjunto; e a necessidade de estimular a integração da equipe multiprofissional de saúde nos diferentes niveis.

Alguns estudos realizados por enfermeiras brasileiras têm mostrado que, apesar da legislação, as unidades de alojamento conjunto ainda não são tão freqüentes como deveriam, mesmo em hospitais públicos. Além disto, em alguns casos, mesmo quando o sistema está disponivel, as condiçōes assistenciais não são aquelas condizentes com a qualidade merecida e quantidade de pessoal de saúde necessária. Ainda é freqüente a atuação de atendentes de enfermagem e de médicos na atenção ao binômio (Scochi; Rocha; Lima, 1997, Scochi et al., 1996, Collet; Rocha, 1996). Portanto, bem longe da necessidade de "estimular a integração da equipe multiprofissional de saúde de diferentes niveis", conforme o preconizado pelo Ministério da Saúde. A atenção à saúde repousa na relação polarizada médico-atendente.

A força de trabalho em alojamentos conjuntos, como nas demais unidades obstétricas e neonatais é eminentemente feminina, e sua caracteristica não difere muito daquelas colocadas na descrição da força de trabalho em enfermagem, em geral, no Brasil. Aliás, de acordo com Tyrrel e Carvalho (1998), desde o primeiro programa de saúde materno-infantil, a enfermagem foi caracterizada pela concepção de "execução" de tarefas e de acordo com o local onde se realizam os cuidados, indicando-se o que deve ser feito e descrevendo-se os procedimentos tradicionais na assistência à mulher e à criança. Suas ações representam medidas de intervenção nas instituições de saúde, buscando racionalizar os recursos humanos, especialmente os da enfermagem, ainda numa concepção taylorista do trabalho.

De modo geral, a assistência ao recém-nascido se institucionaliza no espaço hospitalar, local de trabalho médico e da enfermagem, cabendo aos primeiros a responsabilidade pelo diagnóstico e pela terapêutica e à enfermagem o cuidado direto, o controle do ambiente e a articulação com outros trabalhos e setores. $O$ objeto da ação das práticas de saúde no alojamento 
conjunto tem sido o corpo anátomo-patológico do recém-nascido e da puérpera em suas adaptações à nova vida e as finalidades do trabalho são a manutenção das condições de vitalidade do neonato e fisiológicas da puérpera, a prevenção de infecções e a diminuição da morbi-mortalidade (adaptado de Scochi; Rocha; Lima, 1997).

Não há produção de estudos que versem sobre a força de trabalho e o processo de trabalho especificos em alojamentos conjuntos, porém, minha experiência profissional na área e alguns trabalhos realizados abordando este sistema, de modo amplo, apontam que o mesmo está centrado na concepção da assistência integral da enfermagem ao binômio mãe-filho, facilitando o fortalecimento do vinculo afetivo com o pai e com a familia.

Esta especificidade de trabalho com familias exige que os profissionais de enfermagem tenham qualificação para assistir, além de possuirem dominio teórico/técnico para lidarem com instrumentos de trabalhos (meios) que não são usuais, em sua maioria, nos serviços de saúde. Trata-se da necessidade de aproximar-se do saber da familia e de suas experiências prévias, que estão profundamente imbricadas em vivências culturais anteriores quanto às práticas de saúde de modo mais geral, e quanto aos cuidados com o nascimento, de modo mais específico.

A singularidade desta situação, associada ao fato de ser o nascimento um evento esperado do ciclo da vida - uma vez que ainda é desta forma que os seres humanos aparecem no mundo - coloca em evidência alguns conceitos que só existem na inter-relação: a interação, a comunicação, a relação, a socialização, a cultura. Independente da equipe de saúde, a história dos homens revela que o nascimento sempre ocorreu. Antes em casa, hoje no hospital, mas não se pode negar que a atuação no parto, sempre envolveu diades: mãelrecém-nascido, parturientelparteira, mãelpai; triades: mãelrecém-nascidolparteira, mãelrecém-nascidolpai; e grupos: familia, vizinhos, parentes, comunidade, sociedade. Na instituiçăo-maternidade, esta confluência de atores sociais sempre se mostrou presente. embora nem sempre visivel ou importante para os profissionais de saúde que, em sua maioria, ainda consideram e intervém no processo de nascer como se ele fosse um evento exclusivamente médico (Monticelli, 1998).

O que se observa é que a organização do trabalho em alojamentos conjuntos é bastante diferenciada, dependendo do porte da instituição e também do tipo de financiamento da mesma. Nas instituições-maternidades públicas parece haver uma maior preocupação em atender as normas ministeriais, mantendo uma relativa adequação quanto ao número de profissionais de saúde necessários para a assistência, bem como a participação de pessoal qualificado para a assistência de enfermagem (enfermeiras, técnicas e auxiliares). Nas instituições privadas predomina a ação dos atendentes de enfermagem.

Segundo pesquisa realizada por Scochi et al. (1996) em Ribeirão Preto, observou-se que no alojamento de um hospital privado e de grande porte, a assistência de enfermagem é realizada exclusivamente por atendentes de enfermagem, sendo que a única enfermeira atuante não é exclusiva do setor e executa também atividades administrativas e de controle dos atendentes. Estes últimos realizam todas as ações assistenciais com o binômio, além de também prestarem cuidados imediatos por ocasião do nascimento de parto normal. Certamente, é possivel que a "assistência integral" limite-se ao atendimento dos corpos individuais da puérpera e do recémnascido, com ênfase nos aspectos biológicos e do seguimento à prescrição médica.

Em situações como essa, as ações inerentes à assistência não são desenvolvidas de maneira sistemática, uma vez que dependem de peculiaridades das atendentes. $\mathrm{O}$ estudo revelou que a maioria das trabalhadoras demonstra um trabalho normativo, mecanizado, inespecífico e muitas vezes desenvolvido de modo autoritário. Também ocorre uma diluição de responsabilidades e uma divisão do trabalho que evidencia superposição de papéis e conflitos. No entanto há contraditóriamente, a possibilidade de que o binômio mãe-filho receba uma assistência menos fragmentada, em que pesem as criticas possiveis referentes à competência específica relacionada à não qualificação destas trabalhadoras.

No hospital público, de referência, as autoras observaram que, diferentemente, a equipe 
de enfermagem é composta por enfermeiras, auxiliares, técnicas e atendentes de enfermagem, sendo as auxiliares em maior número. Na divisão pormenorizada do trabalho, atribuem-se às atendentes e auxiliares as atividades manuais de cuidado direto, sendo que as primeiras executam procedimentos mais simples, enquanto as auxiliares administram as medicações prescritas e assistem as crianças com cuidados mais complexos. As enfermeiras ocupam cargos de chefia, realizam intervenções assistenciais de maior complexidade e risco, controle e supervisão, tanto das trabalhadoras, quanto do processo de trabalho. No entanto, quando questionadas, as enfermeiras procuram negar as relações de poder/subordinação com as funcionárias, atribuindo sentido pejorativo à atividade de controle, "talvez por desconhecerem a sua importância dentro do trabalho coletivo ou por a compreenderem como um fim em si mesmo e, portanto, limitando-se em fiscalizar se o procedimento técnico foi ou não cumprido, perdendo de vista a finalidade do trabalho" (Scochi, Rocha, Lima, 1997, p. 164),

Em alojamentos conjuntos que possuem trabalhadoras de enfermagem com diferentes niveis de formação e qualificação (que são a maioria), há a ocorrência sistemática de intervenções educativas, mas também aí há uma divisão de trabalho. Enquanto às técnicas, auxiliares e atendentes cabe a maioria das orientaçöes individuais ou em pequenos grupos sobre cuidados básicos com o recém-nascido, especialmente o banho e os cuidados com o coto umbilical, às enfermeiras cabe a orientação em grupos às puérperas, principalmente por ocasião da alta hospitalar.

Muitos autores têm enfatizado que apenas a implantação do sistema de alojamento conjunto, sem que os diferentes agentes do trabalho cooperativo tenham a dimensão exata dos meios, instrumentos e finalidades do processo de trabalho, não assegura o alcance dos resultados esperados (Scochi, Rocha, Lima, 1997, Scochi et al, 1996. Melleiro, Tronchin, Andreoni, 1998). Sem esta compreensão, a prática assistencial resultará acrítica, com predominância da assistência clínica e com uma filosofia curativa de medicalização do nascimento.

\section{CONSIDERAÇŌES FINAIS}

Trabalhar em alojamentos conjuntos significa, antes de tudo, trabalhar com familias. Esta abordagem tem sido pouco valorizada e, de certa forma, negligenciada na maioria dos hospitais. É necessário que os componentes da força de trabalho em enfermagem tenham preparo específico para lidar com esta realidade. Creio que a educação e a cultura sejam instrumentais (meios) valiosos na formação deste pessoal, seja na qualificação formal ou em projetos de educação continuada.

Como vimos, é a enfermeira quem delega as funçőes, controlando todo o processo de trabalho em alojamentos conjuntos, mas ao mesmo tempo que atribui funçöes aos diferentes membros da equipe, parece eximir-se de seu compromisso com a instrumentalização destes agentes. É com as profissionais de nivel médio e também com os atendentes que ficam as intervenções de cuidado direto e a grande maioria das atividades associadas à educação em saúde. Será que temos instrumentalizado este pessoal para garantir o pleno exercício da assistência integral? Creio que este termo necessite um maior aprofundamento e uma cuidadosa investigação a respeito da integralidade proposta. Como pode-se desenvolver cuidados integrais se não se tem clareza da finalidade destes cuidados? Como colocar em prática uma assistência integral se não há saber qualificado que habilite os profissionais a desenvolverem esta modalidade de trabalho?

Certamente que há, na modalidade de assistência integral, uma divisão menos pormenorizada de trabalho cooperativo, se a compararmos com os cuidados funcionais, mas não é simplesmente a incorporação da primeira que fará com que a divisão desapareça. Além de instrumentalizar a equipe com os conteúdos provenientes das ciências naturais, há necessidade de trabalhar conteúdos das ciências sociais, de relações humanas e de discussões 
que envolvam o próprio processo de trabalho, no seu conjunto.

Também precisa-se ter claro que ter uma compreensão instrumental e tecnológica da assistência não significa estabelecer valores funcionais, tendo em meta somente a efetividade e a eficiência, mas amplamente ancorados nas relações que se estabelecem no sistema de alojamento conjunto, sejam elas intra-equipe, com as familias e em relações de complementaridade com os outros elementos componentes do grupo de trabalho.

Ė importante garantir que esta instrumentalização permita que os sujeitos trabalhadores não apenas sejam especializados ou tecnicamente qualificados, mas que sejam transformados em sujeitos ativos e críticos de seu processo de trabalho.

\begin{abstract}
A theoretical reflection is developed, featuring the characteristics of the Nursing work force in the rooming-in units. A focus is given, along a leading line, to the importance those workers have in caring for the families of newborn children in hospital facilities. The reference basis, adopted as the argumentative development of the text, centers on previous studies and authors covering the work process in Nursing, as well as on the understanding of nursing as a social and historical practice. Reflection is initially developed along considerations of the organization and division of work in health and in nursing. This study also points out the formal and legal origin of Brazilian nursing workers, in order to characterize this work force specifically in the work process carried out by nursing agents of different levels in rooming-in systems at the maternity facilities. The conclusion reached, showed that the work developed in these units requires from the nursing professionals proper qualification to assist the newborn, the puerpera and also the family. They must also demonstrate theoretical/technical command to operate those instruments (means) which are not usually available in the majority of health services.
\end{abstract}

KEYWORDS: work force, work process, rooming-in

RESUMEN: Se trata de una reflexión teórica que apunta las características de la fuerza de trabajo en enfermeria en unidades de alojamiento conjunto. Se circunscribe la importancia que estos trabajadores tienen en el cuidado a los recién nacidos en instituciones hospitalarias. El marco teórico adoptado en la argumentación del texto está centrado en estudios y autores que ven el trabajo en salud y en enfermeria como un proceso y como práctica social e histórica. Inicialmente se tejen consideraciones sobre la organización y la división de trabajo en salud y en enfermeria. Tras ello, se hacen observaciones sobre el origen formal y legal de los trabajadores de enfermeria brasileños, para, finalmente, construir subsidios que caractericen la fuerza de trabajo en enfermeria y,en especifico, en el proceso desarrollado por los agentes de enfermeria en diferentes niveles de los sistemas de alojamiento conjunto de las instituciones-maternidades. Se concluye que el trabajo desarrollado en las unidades de hospitalización exige que los profesionales de enfermeria tengan la calificación especifica para la asistencia a los recién nacidos, a la puérpera y a la familia, además de que tienen que poseer un dominio teórico y técnico para manejar los instrumentos (medios) especificos en los servicios de salud.

PALABRAS CLAVE: fuerza de trabajo, proceso de trabajo, alojamiento conjunto 


\section{REFERÊNCIAS BIBLIOGRÁFICAS}

ALMEIDA, Maria Cecilia P. de et al. A situação da enfermagem nos anos 80 . In: CONGRESSO BRASILEIRO DE ENFERMAGEM, 41., 1989, Florianópolis. Anais...Florianópólis: Ed. da UFSC, 1989 , p. $43-75$.

ALMEIDA, Maria Cecilia Puntel de; ROCHA, Semiramis Melani Melo. Considerações sobre a enfermagem enquanto trabalho. In: ALMEIDA, Maria Cecilia Puntel de; ROCHA, Semiramis M. Melo (Orgs.). O trabalho de enfermagem. São Paulo: Cortez, 1997. p. 15-26.

BEZERRA, Marilia Martins et al. Atendente de enfermagem: por quê? Até quando? Rev. Bras. Enferm. v. 51, n.1, jan./mar., 1998. p. 77-92.

BRASIL, Ministério da Saúde. Normas básicas para alojamento conjunto. Brasilia, 1993.

CAMPOS, Francisco; BRITO, Pedro; RIGOLI, Félix. O campo dos recursos humanos para a saúde no mercosul. In: ORGANIZAÇÃO PANAMERICANA DA SAÚDE. Recursos humanos em saúde no Mercosul. Rio de Janeiro: FIOCRUZ, 1995, p. 31-106.

CAPELLA, Beatriz Beduschi; GELBECKE, Francine Lima. Enfermagem: sua prática e organização. Rev. Bras. Enferm. v. 41, n. 2, p. 132-139, abr./jun., 1988.

COLLET, Neusa; ROCHA, Semiramis M.M. Transformações no ensino das técnicas de enfermagem pediátrica. Goiânia: A.B., 1996.

FONSECA, Rosa M. G. Serpa da. Mulher, trabalho e enfermagem: o nexo coesivo. In: CONGRESSO BRASILEIRO DE ENFERMAGEM, 47., 1995, Goiânia. Anais...Goiânia: Ed. da UFG, 1996. p. 79-90.

GOMES, Maysa Lduvice. Um encontro de mulheres-dar à luz. Rio de janeiro: UNI-RIO, 1996. Dissertação (Mestrado em Enfermagem) - Curso de Pós-Graduação em Enfermagem, Universidade do Rio de Janeiro, 1996

KAKEHASHI, Tereza Y. A situação atual da enfermagem neonatológica e suas tendências para o futuro. Acta Paul. Enf., v.9, 1996, p. 17-22. Nủmero especial.

KANTORSKI, Luciane P. As transformaçōes do mundo do trabalho e a questão da saúde - algumas reflexōes preliminares. Rev. Latino-Americana de Enf., v. 5, n. 2, abr. 1997. p. 5-16.

KITZINGER, Sheila. Mảes: um estudo antropológico da maternidade. 2.ed. Portugal: Presença, 1996.

LOPES, Marta Júlia. Pensando mulher, saúde e trabalho no hospital. Rev. Gaúcha. Enf., v. 13, n. 1, p. 34-36. jan. 1992.

MACHADO, Maria Helena. A participação da mulher na força de trabalho em saúde no Brasil - 197080. In: MÉDICl, André Cézar et al. Textos de apoio - Planejamento I - Recursos humanos em saúde. Rio de Janeiro: PEC/ENSP, 1987. p. 51-62.

MARSIGLIA, Regina Maria G. Unidades básicas de serviços de saúde: disponibilidade tecnológica, processos de trabalho e recursos humanos. In: SPINOLA, Aracy Witt de Pinho et al. (Org.). Pesquisa social em saúde. Sāo Paulo: Cortez, 1992. p. 213-224.

MARX, Karl. O capital: critica da economia politica. 3.ed. Rio de Janeiro: Civilização Brasileira, 1975. v. 6 . 
MEDEIROS, Luzia Cecilia de. O papel do enfermeiro hoje. Rev. Bras. Enferm. v. 50, n. 2, p. 275-290. abr./jun. 1997.

MÉDICl, André Cezar. A força de trabalho em saúde no Brasil dos anos 70: percalços e tendências. In: $\mathrm{MÉDICl}$, André Cézar et al. Textos de apoio - Planejamento I - Recursos humanos em saúde. Rio de Janeiro: PEC/ENSP, 1987, p. 39-50.

MÉDICI, André Cezar; PAIM, Elza Ramos. Estrutura e dinåmica da força de trabalho em enfermagem In: MEDICl, André Cézar et al. Textos de apoio - Planejamento I - Recursos humanos em saúde. Rio de Janeiro: PEC/ENSP, 1987. p. 124-140

MELLEIRO, Marta Maria: TRONCHIN, Daisy M.R.; ANDREONI, Sandra O processo de cuidar na perspectiva de enfermeiros de um hospital de ensino. In: CIANCIARULLO, Tamara I.; GUALDA, M.R.: MELLEIRO, Marta M. Indicadores de qualidade: uma abordagem perinatal. São Paulo: Ícone, 1998. Cap. 4, p. 55-65.

MONTICELLI, Marisa. Abordagem cultural do nascimento como um rito de passagem. Acta Paul. Enf., v.9, 1996. p. 41-44. Número especial.

Aproximaçōes culturais entre profissionais de enfermagem e familias, no contexto do nascimento hospitalar. Projeto de pesquisa apresentado à seleção ao Curso de Doutorado em Enfermagem/UFSC. Florianópolis. 1998. (texto digitado).

NOGUEIRA, Roberto Passos. A força de trabalho em saúde. In: MÉDICl, André Cézar et al. Textos de apoio - Planejamento I - Recursos humanos em saúde. Rio de Janeiro: PEC/ENSP. 1987. p. 13-16.

PIRES, Denise. Reestruturação produtiva e trabalho em saúde no Brasil. São Paulo: Annablume, 1998.

Organização da enfermagem na sociedade contemporânea. Documento apresentado como parte do temário oficial do $49^{\circ}$ Congresso Brasileiro de Enfermagem, Belo Horizonte, 1997 (Mimeogr.).

Hegemonia médica na saúde e a enfermagem. São Paulo: Cortez, 1989.

REZENDE, Ana Lúcia Magela de. Saúde: dialética do pensar e do fazer. São Paulo: Cortez. 1986.

ROSA, Maria Tereza Leopardi et al. O desenvolvimento técnico-cientifico da enfermagem - uma aproximação com instrumentos de trabalho. In: CONGRESSO BRASILEIRO DE ENFERMAGEM, 41., 1989, Florianópolis. Anais...Florianópolis: Ed da UFSC. 1989. p. 97-126.

SILVA, Graciette Borges da. Enfermagem profissional: análise critica. 2. ed. Săo Paulo: Cortez, 1989.

SCOCHI, Carmen G.S et al. O alojamento conjunto em hospitais-maternidade do municipio de Ribeirāo Preto: análise da assistència. Acta Paul. Enf., v.9, n.3, set./dez. 1996. p. 15-23.

SCOCHI, Carmen G.S.; ROCHA, Semiramis M.M.; LIMA, Regina A.G de. A organização do trabalho em unidades neonatais. In: ALMEIDA, Maria Cecilia P. de.; ROCHA, Semiramis M.M. (Orgs.). O trabalho de enfermagem. Săo Paulo: Cortez, 1997. Cap.5, p. 151-174.

TORREZ, Milta N. F. Barron. A influência da ABEn nos diferentes âmbitos da enfermagem: a qualificação da força de trabalho. In: CONGRESSO BRASILEIRO DE ENFERMAGEM, 48., 1996, São Paulo. Anais... Săo Paulo: FAPESP, 1997. p. 240-246. 
TYRREL, Maria Antonieta R., CARVALHO, Vilma de. Programas nacionais de saúde materno-infantil: papel do Estado, da mulher e da enfermagem. In: CIANCIARULLO, Tamara I., GUALDA, M.R., MELLEIRO, Marta M. Indicadores de qualidade: uma abordagem perinatal. São Paulo: İcone, 1998. Cap. 3, p. 43-53.

UNGERER, Regina L.S.; MIRANDA, Ana T.C. de. História do alojamento conjunto. Jornal de Pediatria, v.75, n.1, jan./fev. 1999, p. 5-10.

VALE, Eucléa Gomes et al. A enfermagem no mundo: a situação brasileira. Documento apresentado como parte do temário oficial do $51^{\circ}$ Congresso Brasileiro de Enfermagem, Florianópolis, 1999. (Mimeogr.). 